\title{
Manajemen Pemupukan Tanaman Kelapa Sawit (Elaeis Guineensis Jacq.) Di Pelantaran Agro Estate, Kalimantan Tengah
}

\section{Management of oil palm fertilization in Pelantaran Agro Estate, Center Kalimantan}

\author{
S. Manahan Panggabean, Purwono* \\ Departemen Agronomi dan Hortikultura, Fakultas Pertanian, Institut Pertanian Bogor (Bogor Agricultural \\ University), Jl. Meranti, Kampus IPB Darmaga, Bogor 16680, Indonesia \\ Telp.\&Faks. 62-251-8629353 e-mail agronipb@indo.net.id \\ *Penulis untuk korespondensi: puripb@gmail.com
}

Disetujui 6 November 2017/Published online 14 November 2017

\begin{abstract}
The research was conducted in Pelantaran Agro Estate, Center Kalimantan starting February 14 until June 14, 2011. The research was study and understand management of oil palm fertilization. Data was collected from primary and secondary source. Primary data were analized on the effectiveness (right time, right type, right dose, right methods), labor effisiency, and nutrient deficiency. Fertilization management in Pelantaran Agro Estate (PAGE) has generally been implemented in accordance with the standards of the fertilizing. The garden has been paying attention to the provisions and recommendations that have been recommended fertilizing and has been referred to the principle of $4 \mathrm{~T}$ (right time, right type, right dose, and right methods) in terms of achieving the effectiveness and efficiency of fertilization. However, in the use of labor yet efficient which certainly have an impact on the efficiency of the time and cost. Realization of fertilization has not been fully implemented in accordance with the recommendation. Constraints in the implementation of the fertilizing still found in the marshy and corrugated area
\end{abstract}

Keywords : effectiveness, efficiency, fertilization, palm oil

\begin{abstract}
ABSTRAK
Penelitian dilakukan di Pelantaran Agro Estate, Kalimantan Pusat mulai 14 Februari sampai 14 Juni 2011. Penelitian belajar dan memahami pengelolaan pembuahan kelapa sawit. Data dikumpulkan dari sumber primer dan sekunder. Data primer dianalisis mengenai keefektifan (waktu tepat, jenis kanan, dosis benar, metode yang benar), efisiensi tenaga kerja, dan kekurangan nutrisi. Pengelolaan pemupukan di Pelantaran Agro Estate (PAGE) pada umumnya telah dilaksanakan sesuai dengan standar pemupukan. Taman tersebut telah memperhatikan ketentuan dan rekomendasi yang telah direkomendasikan pemupukan dan telah mengacu pada prinsip $4 \mathrm{~T}$ (waktu yang tepat, jenis hak, dosis tepat, dan metode yang benar) dalam hal mencapai efektivitas dan efisiensi pemupukan. . Namun, dalam penggunaan tenaga kerja belum efisien yang tentunya berdampak pada efisiensi waktu dan biaya. Realisasi pemupukan belum sepenuhnya dilaksanakan sesuai dengan rekomendasi. Hambatan dalam penerapan pemupukan masih ditemukan di daerah berawa dan bergelombang.
\end{abstract}

Kata kunci : efektivitas, efisiensi, kelapa sawit, pemupukan 


\section{PENDAHULUAN}

Kelapa sawit (Elaeis guineensis Jacq.) sebagai tanaman pendatang dari Afrika Barat ternyata budidayanya di Indonesia telah berkembang sangat pesat dan sampai saat ini masih merupakan penghasil utama devisa negara dari sektor pertanian. Lahan-lahan yang secara agronomis sesuai dan diperuntukkan penggunaan tanahnya bagi kelapa sawit telah memberikan dampak positif dalam perkembangan daerah dan peningkatan taraf hidup masyarakat (Adiwiganda, 2007).

Kelapa sawit di Indonesia terus berkembang dari tahun ke tahun, baik itu pertambahan luas areal dan peningkatan produksi. Data pada tahun 2009 menunjukkan luas areal kebun kelapa sawit adalah 7.5 juta ha dan produksi CPO 18.6 juta ton. Pada tahun 2010 luas areal kebun meningkat menjadi 7.8 juta ha dan produksi CPO 19.8 juta ton (Direktorat Jenderal Perkebunan, 2010).

Produktivitas tanaman kelapa sawit yang tinggi dapat dicapai dengan pemeliharaan yang intensif. Salah satu faktor utama yang berpengaruh dalam pertumbuhan dan produktivitas kelapa sawit adalah pemupukan. Pemupukan merupakan pemberian unsur hara ke dalam tanah untuk menjaga keseimbangan hara yang dibutuhkan tanaman dan mengganti hara yang hilang terbawa hasil panen.

Adiwiganda (2007) menyatakan bahwa pemupukan pada kelapa sawit secara rutin dan cukup serta berimbang menjadi lebih penting karena kemampuan dari kelapa sawit untuk mengabsorbsi unsur hara yang jauh di dalam tubuh tanah adalah rendah. Penyebaran feeding root (penyerapan akar) kelapa sawit terbatas pada 0-60 cm. Selain itu kondisi kesuburan tanah pada kedalaman 0-60 cm juga sangat dipengaruhi oleh variasi iklim yang cenderung menurunkan tingkat kesuburan tanah, baik dalam kondisi terlalu kering maupun terlalu basah.

Menurut Poeloengan et al. (2003) pemupukan menjadi satu keharusan karena kelapa sawit tergolong tanaman yang sangat konsumtif. Kekurangan salah satu unsur hara akan segera menunjukkan gejala defisiensi dan mengakibatkan pertumbuhan vegetatif terhambat serta produksi menurun. Selanjutnya Adiwiganda (2007) menyatakan bahwa upaya pemupukan pada tanaman kelapa sawit harus dapat menjamin pertumbuhan vegetatif dan generatif yang normal sehingga dapat memberikan produksi tandah buah segar (TBS) yang optimal serta menghasilkan minyak sawit mentah (CPO) yang tinggi baik kuantitas maupun kualitasnya.
Keefektifan pemupukan adalah pemupukan yang berfungsi menambahkan unsur hara yang tersedia dalam jumlah sedikit di dalam tanah. Keefektifan pemupukan berhubungan dengan tingkat/persentase hara pupuk yang diserap tanaman. Efisiensi pemupukan dapat dicapai bila perhitungan takaran pupuk yang tepat. Takaran pupuk yang tepat dipengaruhi oleh hubungan antara sifat-sifat tanah dan produksi tanaman serta metode perhitungan takaran pupuk yang tepat. Keefektifan dan efisiensi pemupukan pada tanaman kelapa sawit yang belum optimal akan menghambat pertumbuhan vegetatif dan generatif kelapa sawit. Produksi TBS tidak optimal dan turunnya kualitas serta kuantitas minyak mentah. Hal ini terjadi karena dalam manajemen pemupukan terjadi penyimpangan di lapangan perkebunan kelapa sawit (Riwandi, 2002).

Untuk mencapai keefektifan dan efisiensi pemupukan pada kelapa sawit maka manajemen pemupukan di lapangan harus diupayakan seoptimal mungkin, antara lain pemupukan kelapa sawit rutin dan cukup serta berimbang, jenis pupuk, dosis pupuk, waktu dan cara aplikasi pemupukan yang tepat, serta pengawasan pemupukan yang lebih tepat. Penelitian ini bertujuan untuk mempelajari dan memahami manajemen pemupukan tanaman kelapa sawit.

\section{BAHAN DAN METODE}

Penelitian dilaksanakan di Kebun Pelantaran Agro Estate (PAGE), Kalimantan Tengah mulai 14 Februari sampai 14 Juni 2011. Kegiatan pengumpulan data yang dilakukan selama penelitian yaitu dengan metode langsung (data primer) dan tidak langsung (data sekunder). Data primer diperoleh dari pengamatan pada kegiatan pemupukan meliputi prestasi tenaga kerja, ketepatan dosis pemupukan, dan ketepatan cara aplikasi. Prestasi tenaga kerja pemupuk diamati berdasarkan bobot pupuk/HK kemudian dibandingkan dengan prestasi kerja yang ditetapkan kebun. Prestasi kerja berdasarkan bobot pupuk/HK yang diamati meliputi jenis pupuk, jumlah pupuk, dan jumlah tenaga kerja dalam satu pada satu blok. Ketepatan dosis pemupukan diamati pada saat penguntilan. Pengamatan ketepatan dosis untilan dilakukan pada satu grup penguntil. Pengamatan dilakukan selama tiga hari dengan mengambil sampel 30 untilan. Untuk mengetahui ketepatan penguntilan dilakukan dengan menimbang bobot untilan kemudian dibandingkan dengan bobot standar per untilan yang ditetapkan oleh kebun. Ketepatan cara aplikasi pemupukan dilakukan pada dua baris 
tanaman yang dipilih dari aplikasi pupuk tiap penabur. Jumlah penabur yang diamati sebanyak 10 orang. Penentuan ketepatan cara didasarkan pada ketentuan jarak tabur dan kondisi penyebaran pupuk sesuai dengan standar kebun. Data sekunder diperoleh dari arsip perusahaan meliputi data kondisi kebun, data kondisi tanaman, dan standar kebun pada kegiatan penanaman, pemeliharaan, pemanenan dan tenaga kerja.

\section{HASIL DAN PEMBAHASAN}

\section{Kondisi umum}

Kebun kelapa sawit Pelantaran Agro
Estate (PAGE) berada di provinsi Kalimantan Tengah dengan letak geografis pada koordinat antara 112.95-113.01 ${ }^{\circ} \mathrm{BT}$ dan $2.01-2.11^{\circ} \mathrm{LS}$. Rata-rata curah hujan 3100 mm per tahun. Grafik curah hujan selama penelitian ditampilkan pada gambar 1 . Suhu rata-rata harian adalah $27^{\circ} \mathrm{C}$ kisalan $23-33^{\circ} \mathrm{C}$. PAGE terdapat 4 jenis tanah, yaitu ultisol (podsolik), inceptisol (Aluvial/Kaolin), histosol (gambut), dan entisol (pasir). Kondisi lahan kebun ini mempunyai topografi datar hingga bergelombang. Kelas lereng 0-8 \% (datar) dan 9-15\% (begelombang). Berdasarkan kelas kesesuaian lahannya sebagian besar lahan di PAGE tergolong S3 sedangkan sebagian lagi masuk kedalam kelas lahan S2.

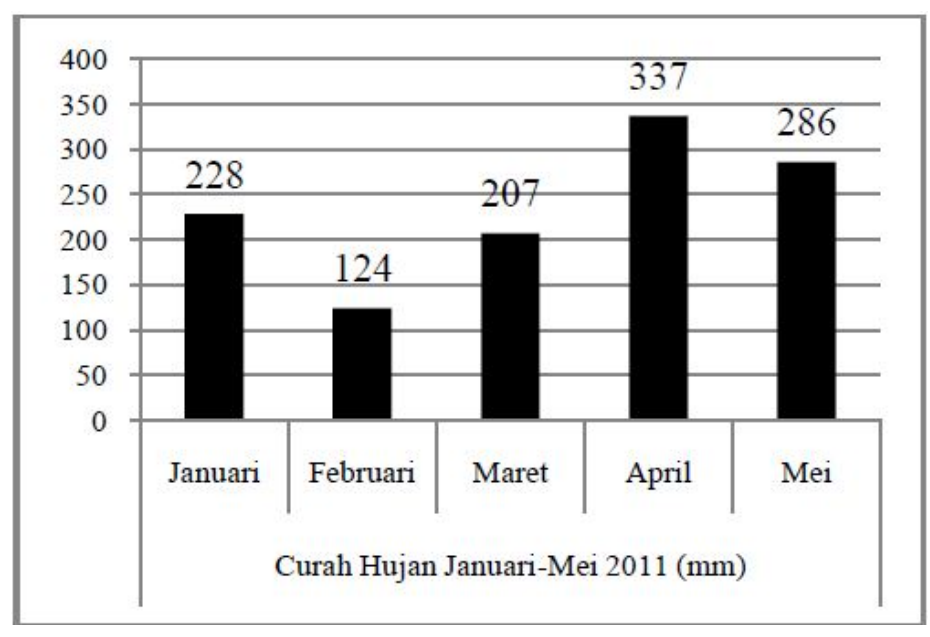

Gambar 1. Grafik curah hujan Pelantaran Agro Estate Januari-Mei 2011

Luas areal yang diusahakan di PAGE adalah 2698 ha, yang terdiri atas tanaman menghasilkan tahun tanam 2004-2008. PAGE menggunakan bebarapa jenis bibit yang ditanam antara lain: ASD/Costarica, Marihat V, PPKS, Socfindo, dan PNG. Jarak yang tanam yang digunakan pada umumnya adalah $9.2 \mathrm{~m}$ x $9.2 \mathrm{~m}$ x 9.2 m dengan populasi per hektar 136 pokok. Produksi kelapa sawit yang dihasilkan di PAGE pada empat tahun terakhir mengalami peningkatan. Perkembangan produksi di PAGE tahun 2007-2010 disajikan pada Tabel 1.

\section{Pengamatan ketepatan dosis untilan}

Keefektifan dan efisiensi pemupukan ditentukan oleh pengelolaan pemupukan yang tepat. Pemupukan yang efektif dan efisien mengacu pada konsep 4T yaitu: tepat jenis, tepat dosis, tepat dan tepat cara. Dasar pertimbangan yang digunakan dalam penentuan jenis pupuk antara lain: umur tanaman, gejala defisiensi hara, kondisi lahan dan harga pupuk (Poeloengan et al., 2003). Aplikasi jenis pupuk yang digunakan PAGE adalah berdasarkan buku rekomendasi pemupukan yang dikeluarkan oleh Departement Research BGA. Dasar penyusunan rekomendasi pemupukan adalah hasil analisa daun, jenis tanah, status hara, dan potensi produksi. Jenis pupuk yang digunakan PAGE pada tahun 2011 adalah pupuk tunggal. Pupuk tunggal yang digunakan antara lain: Rock Phospate untuk memenuhi kebutuhan unsur $\mathrm{P}$, kieserit untuk memenuhi kebutuhan unsur Mg, urea untuk memenuhi unsur N, MOP (Muriate of Potash) untuk memenuhi kebutuhan unsur K, HGFB (High Grade Fertilizer Borate) untuk memenuhi kebutuhan unsur B, dan Chelated Zincoper untuk memenuhi kebutuhan unsur $\mathrm{Zn}$ dan $\mathrm{Cu}$. 
Tabel 1. Produksi dan produktivitas TBS di PAGE tahun 2007-2010

\begin{tabular}{llcccc}
\hline \multirow{2}{*}{ Tahun tanam } & \multicolumn{1}{c}{ Uraian } & \multicolumn{3}{c}{ Tahun } \\
\cline { 3 - 6 } 2004 & Produksi (ton) & 1023.40 & 6504.82 & 10973.38 & 12655.01 \\
& Luas Panen (ha) & 669.01 & 741.01 & 740.2 & 740.2 \\
\multirow{2}{*}{2005} & Produktivitas (ton/ha) & 1.53 & 8.78 & 14.82 & 17.1 \\
& Produksi (ton) & 59.19 & 2052.62 & 3901.76 & 5558.09 \\
& Luas Panen (ha) & 287.56 & 486.76 & 485.9 & 485.9 \\
2006 & Produktivitas (ton/ha) & 0.21 & 4.22 & 8.03 & 11.44 \\
& Produksi (ton) & & & 3848.46 & 4974.92 \\
& Luas Panen (ha) & & & 611.86 & 611.86 \\
& Produktivitas (ton/ha) & & 6.29 & 8.13 \\
& Produksi (ton) & & & 131.15 & 3712.23 \\
& Luas Panen (ha) & & & 822.33 & 822.34 \\
& Produktivitas (ton/ha) & & & 0.16 & 4.51 \\
& Produksi (ton) & & 0.46 & 52.25 \\
& Luas Panen (ha) & & & 37.97 & 37.97 \\
& Produktivitas (ton/ha) & & & 0.01 & 1.38 \\
\hline
\end{tabular}

Menurut PPKS (2003), biaya per unit hara dalam pupuk tunggal masih lebih rendah dibandingkan dengan pupuk majemuk atau jenis pupuk lainnya. Akan tetapi biaya aplikasi pupuk tunggal menjadi lebih mahal karena hanya satu jenis hara saja yang diaplikasikan pada setiap aplikasi pemupukan. Sutarta et al. (2003) menambahkan pupuk tunggal umumnya mengandung satu hara utama, walaupun beberapa pupuk tunggal juga mengandung hara lainnya tetapi biasanya dalam jumlah yang rendah. Selain itu, adanya pupuk tunggal memungkinkan aplikasi setiap unsur hara sesuai dengan yang diinginkan.

Tabel 2. Ketepatan dosis untilan pupuk HGFB (High Grade Fertilizer Borate)

\begin{tabular}{cccc}
\hline $\begin{array}{c}\text { Jumlah tenaga kerja } \\
\text { (orang) }\end{array}$ & Bobot/Until (Kg) & Rataan & Tepat Dosis (\%) \\
\hline 6 & 6.8 & 6.63 & 97.5 \\
6 & 6.8 & 6.36 & 93.52 \\
6 & 6.8 & 6.29 & 92.5 \\
\hline Rata-rata & & 94.5 \\
\hline
\end{tabular}

Penentuan ketepatan dosis pemupukan PAGE berdasarkan buku rekomendasi pemupukan yang dikeluarkan oleh pihak research. Dasar penyusunan dosis pemupukan adalah hasil analisa daun, jenis tanah, status hara, dan potensi produksi. Adiwiganda (2007) mengemukakan bahwa dosis pupuk yang direkomendasikan didasarkan pada berbagai faktor antara lain: unsur hara yang terbawa saat panen, unsur hara yang termobilisasi dalam batang dan pelepah, serta estimasi kehilangan unsur hara. Tabel 2 menyajikan data rata-rata ketepatan dosis pemupukan pupuk HGFB sebesar $94.5 \%$. Tabel 3 menyajikan data ratarata ketepatan dosis pemupukan pupuk RP sebesar $94.5 \%$

Tabel 3. Ketepatan dosis untilan pupuk RP (Rock Phospate)

\begin{tabular}{cccc}
\hline $\begin{array}{c}\text { Jumlah tenaga kerja } \\
\text { (orang) }\end{array}$ & Bobot/Until (Kg) & Rataan & Tepat Dosis (\%) \\
\hline 6 & 8.5 & 8.1 & 95.33 \\
6 & 8.5 & 7.75 & 91.2 \\
6 & 8.5 & 8.2 & 96.51 \\
\hline Rata-rata & & & 94.35 \\
\hline
\end{tabular}

Penimbangan sampel dilakukan sebanyak 30 karung until pada setiap penguntilan. Hasil pengamatan diperoleh bahwa persentase ketepatan untilan yang dilakukan oleh 
penguntil memiliki rata-rata ketepatan $94.50 \%$ untuk HGFB dan $94.50 \%$ untuk RP (standar kebun adalah $\geq 90 \%$ ). Hal ini menunjukkan bahwa tenaga kerja penguntil sudah terlatih dalam menguntil pupuk sesuai dengan jenis dan dosis pupuk. Standar kerja dalam kegiatan penguntilan adalah $1500 \mathrm{~kg} / \mathrm{HK}$. Tabel 4 menyajikan persentase tenaga kerja pemupuk. Tenaga kerja pemupuk sudah mencapai standar kebun.

Tabel 4. Persentase tenaga kerja pemupuk

\begin{tabular}{|c|c|c|c|c|c|c|}
\hline Tanggal & Jenis Pupuk & Dosis/ pokok (kg) & Standar (kg) & $\begin{array}{l}\text { Jumlah Pupuk } \\
\text { (kg) }\end{array}$ & $\begin{array}{l}\text { Jumlah tenaga kerja } \\
\text { (orang) }\end{array}$ & $\begin{array}{l}\text { Prestasi } \\
(\mathrm{kg} / \mathrm{HK})\end{array}$ \\
\hline $22 / 03 / 11$ & $\mathrm{RP}$ & 2 & 500 & 8500 & 17 & 500 \\
\hline 23/03/11 & $\mathrm{RP}$ & 2 & 500 & 8500 & 17 & 500 \\
\hline $24 / 03 / 11$ & $\mathrm{RP}$ & 2 & 500 & 11000 & 21 & 523.8 \\
\hline 25/03/11 & $\mathrm{RP}$ & 2 & 500 & 5668 & 14 & 404.85 \\
\hline 26/03/11 & $\mathrm{RP}$ & 2 & 500 & 12470 & 23 & 542.17 \\
\hline 29/03/11 & Kieserit & 1.25 & 450 & 7650 & 18 & 425 \\
\hline 30/03/11 & Kieserit & 1.25 & 450 & 7650 & 17 & 450 \\
\hline 31/03/11 & Kieserit & 1.25 & 450 & 7650 & 17 & 450 \\
\hline 1/4/2011 & Kieserit & 1.25 & 450 & 6394 & 18 & 355.22 \\
\hline 2/4/2011 & Kieserit & 1.25 & 450 & 7650 & 17 & 450 \\
\hline
\end{tabular}

Aplikasi pupuk di lapangan sudah dilakukan dengan cukup tepat. Pelangsir meletakkan jumlah karung until sesuai dengan kelipatan dosis per pokok. Pupuk RP dengan dosis $2 \mathrm{~kg} /$ pokok, pelangsir meletakkan 8 karung until, kieserit dengan dosis $1.25 \mathrm{~kg} /$ pokok diletakkan 5 karung until, urea dengan dosis 1 kg/pokok diletakkan 4 karung until untuk dua baris tanaman sampai pasar tengah (jumlah 34 pokok), dan HGFB dengan dosis $0.1 \mathrm{~kg} /$ pokok diletakkan 1 karung until untuk dua baris tanaman penuh (jumlah 68 pokok). Selain itu, pengecer juga telah meletakkan karung until dalam baris tanaman sesuai dengan kelipatan dosis per pokok. Demikian juga untuk penabur telah menggunakan takaran sesuai dengan jenis dan pupuk yang diaplikasikan.

Waktu pemupukan di Pelantaran Agro Estate (PAGE) dilakukan dua kali aplikasi yaitu semester pertama (Januari-Juni) dan semester kedua (Juli-Desember). Aplikasi pemupukan kebun PAGE dilakukan berdasarkan buku rekomendasi pemupukan 2011 yaitu untuk aplikasi pupuk RP dan kieserit dilakukan sekali dalam setahun pada semester pertama, sedangkan aplikasi pupuk urea, MOP, HGFB, dan Chelated Zincoper dilakukan dua kali dalam setahun. Urutan aplikasi pemupukan yang dilaksanakan yaitu RP-HGFB/Chelated Zincoper-kieserit-urea-MOP.

Salah satu faktor yang berpengaruh terhadap waktu aplikasi pemupukan adalah iklim (curah hujan). Adiwiganda (2007) menyatakan bahwa kesulitan pelaksanaan pemupukan tepat waktu adalah diakibatkan terutama oleh terjadinya deviasi iklim (curah hujan) yang sulit diprediksi yaitu kandungan air dalam tanah yang tidak sesuai dengan persyaratan untuk aplikasi pemupukan. Curah hujan PAGE pada JanuariMei 2011 dapat dilihat pada Gambar 2 dan waktu aplikasi pemupukan aplikasi pemupukannya dapat dilihat pada Tabel 5. Pemupukan yang optimum dilakukan pada saat curah hujan 100-200 mm/bulan dan minimum pada curah hujan $60 \mathrm{~mm} / \mathrm{bulan}$ serta maksimun $300 \mathrm{~mm} / \mathrm{bulan}$. Jika terjadi kemarau dengan curah hujan kurang dari $60 \mathrm{~mm} / \mathrm{bulan}$ maka pemupukan dihentikan dan dapat dilaksanakan pemupukan kembali jika sudah turun hujan $50 \mathrm{~mm} / 10$ hari. Namun jadwal aplikasi diatas dapat dilaksanakan dengan asumsi hanya faktor iklim yang menjadi faktor pembatas, sedangkan faktor lain seperti ketersediaan pemupukan, kesiapan lahan, dan ketersediaan tenaga kerja dapat dikendalikan.

Hasil pengamatan, rata-rata curah hujan tiap bulan di Pelantaran Agro Estate Januari-Mei 2011 yaitu 236 mm/bulan. Pada umumnya waktu aplikasi pemupukan dilaksanakan pada saat curah hujan yang ideal untuk aplikasi per bulannya yaitu 60-300 mm/bulan. Namun waktu aplikasi pemupukan HGFB kurang tepat yaitu pada curah hujan $337 \mathrm{~mm} / \mathrm{bulan}$ (>300 $\mathrm{mm} /$ bulan). Sesuai dengan rekomendasi dari research departement, bulan yang curah hujan lebih dari $300 \mathrm{~mm} /$ bulan aplikasi pupuk Urea, MOP, dan HGFB dihindari untuk meminimalisir pencuncian, aliran air, dan erosi. Pada areal yang konservasi tanah dan airnya telah dilaksanakan secara baik, faktor pembatas ini dapat ditiadakan. 
Tabel 5. Aplikasi pemupukan Pelantaran Agro Estate 2011

\begin{tabular}{|c|c|c|c|c|c|c|c|c|c|c|}
\hline \multirow{2}{*}{ Jenis pupuk } & \multicolumn{10}{|c|}{ Bulan aplikasi } \\
\hline & 1 & 2 & 3 & 4 & 5 & 6 & 7 & 8 & 9 & 10 \\
\hline $\mathrm{RP}$ & $\mathrm{R} 1$ & R1 & & & & & & & & \\
\hline HGFB & & R1 & & & & & R2 & R2 & & \\
\hline C.Zinc & & R1 & & & & & R2 & R2 & & \\
\hline Urea & & & & & R1 & R1 & & & R2 & R2 \\
\hline MOP & & & & & R1 & R1 & & & R2 & R2 \\
\hline Kieserit & & & R1 & & & & & & & \\
\hline
\end{tabular}

Keterangan : R1 = aplikasi pupuk rotasi pertama; R2 = aplikasi pupuk rotasi kedua

Keefektifan dan efisiensi pemberian pupuk juga dipengaruhi oleh metode pupuk yang digunakan. Cara penaburan pupuk pada intinya diaplikasikan di daerah perakaran yang dominan menyerap hara. Cara dan tempat penaburan pupuk yang diaplikasikan berpengaruh terhadap persentasi pupuk yang diserap oleh tanaman. Cara penaburan yang dilakukan oleh PAGE adalah manual yaitu dengan ditebar secara merata pada piringan (broadcast) dan dibenam (pocket). Jenis pupuk yang ditebar adalah RP, Kieserit, Urea, MOP, dan HGFB dengan jarak tabur dari tanaman 1-3 m dari batang tanaman.
Penyebaran pupuk pada tanaman menghasilkan (TM) berbentuk huruf "U” mengikuti susunan pelepah. Jenis pupuk yang dibenam adalah Chelated Zincoper pada jarak $50 \mathrm{~cm}$ dari pokok tanaman. Pengamatan ketepatan cara pada aplikasi pupuk kieserit pada satu blok. Ketepatan cara diamati dari jarak taburnya dan kondisi penyebaran pupuk. Penulis mengamati 10 tenaga kerja penabur yang sama. Tanaman yang diamati adalah dua baris hingga pasar tengah untuk setiap penabur. Hasil pengamatan ketepatan cara aplikasi pupuk dapat dilihat pada gambar 2 .

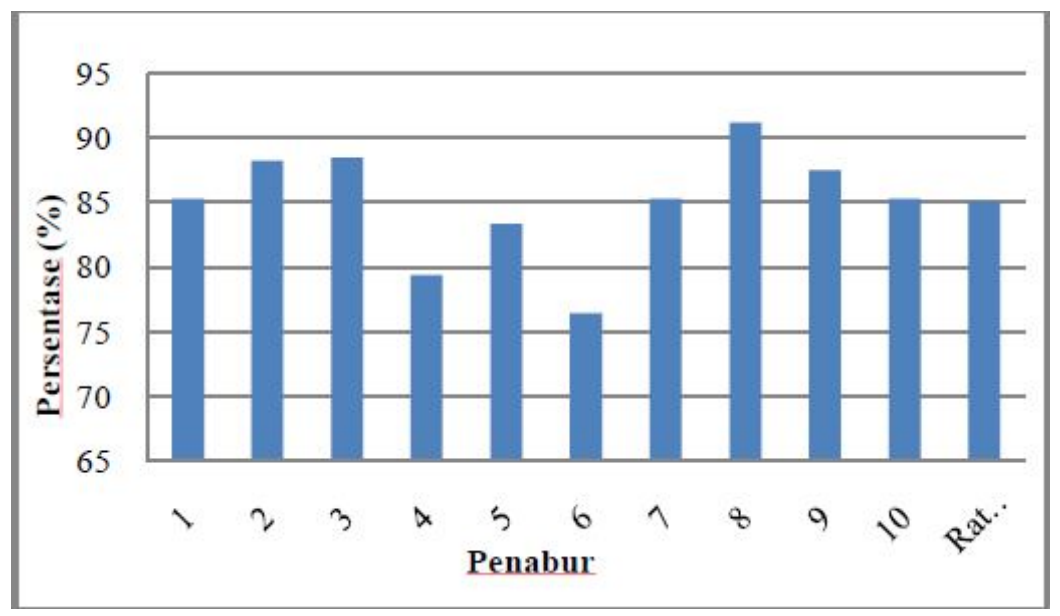

Gambar 2. Grafik ketepatan cara aplikasi pupuk Kieserit di Blok D04

Hasil pengamatan tepat cara, bahwa ratarata ketepatan cara tenaga kerja penabur untuk pupuk kieserit sudah mencapai 85\%. Hal ini menunjukkan bahwa cara aplikasi pupuk yang dilaksanakan sudah cukup tepat. Namun masih di bawah standar kebun yaitu $\geq 90 \%$. Pelaksanan pemupukan sebenarnya sudah memperhatikan tempat dalam aplikasinya yaitu pada piringan, sudah memperhatikan kondisi penyebaran pupuk yaitu ditebar secara merata pada piringan, pupuk tidak menggumpal karena sudah dilakukan penguntilan terlebih dahulu, dan telah memperhatikan jarak tabur dengan mempertimbangkan penyebaran akar yang aktif menyerap hara dalam tanah. Akan tetapi pada saat menjelang waktu kerja selesai, tenaga kerja penabur akan lebih mengutamakan target output tercapai duluan.
Gambar 2 menunjukkan bahwa tenaga kerja penabur memperoleh persentase ketepatan cara yang tidak merata. Hal ini disebabkan beberapa faktor antara lain: beberapa penabur dari awal kerja lebih mementingkan output/HK tercapai sehingga mengesampingkan penaburan secara tepat. Tenaga kerja penabur mengacu pada prinsip asalkan pupuk sudah tertabur pada tanaman. Tenaga kerja penabur yang masih baru dapat dikatakan belum memiliki kapasitas yang memadai jika dibandingkan penabur yang sudah lama. Selain itu disebabkan oleh faktor usia penabur.

\section{Efisiensi tenaga kerja}

Penentuan jumlah tenaga kerja pemupuk berpengaruh penting terhadap kegiatan 
pemupukan. Perlu dilakukan penghematan tenaga kerja dengan menyusun organisasi kerja yang lebih efektif dan efisien serta melengkapi fasilitas lapangan. Adiwiganda (2007) menyatakan bahwa tenaga penabur pupuk harus memiliki kualitas dan kapasitas yang memadai. Tenaga kerja merupakan karyawan harian tetap (KHT), sehingga pengarahan kerja lebih mudah dilaksanakan.

Basis untuk tiap tenaga kerja penabur adalah 450-500 kg/HK pada hari biasa (7 jam) kerja, sedangkan pada hari Jumat (5 jam) basis dikurangi yaitu 300-350 kg/HK sesuai dengan jenis dan dosis pupuk. Berdasarkan Tabel 9, ratarata prestasi tenaga kerja penabur berdasarkan bobot pupuk yang diaplikasikan di lapangan pada umumnya telah mencapai standar kebun. Khusus pada hari Jumat prestasi kerja dikurangi dari prestasi kerja hari biasa. Namun terkadang basis tidak tercapai sesuai dengan standar kebun seperti pada tanggal 29 Maret 2011. Hal ini disebabkan persediaan pupuk di gudang pada hari tersebut habis dan berakibat kepada tidak efisiennya penggunaan tenaga kerja, waktu dan biaya. Pemupukan menjadi lebih awal selesai dari waktu kerja biasa. Biaya pemupukan menjadi lebih besar. Sebagai contoh pada Tabel
10, dengan output/HK adalah $450 \mathrm{~kg}$ dan jumlah pupuk $7650 \mathrm{~kg}$ maka jumlah tenaga kerja yang dibutuhkan seharusnya adalah 17 orang, bukan 18 orang. Dari segi waktu kerja lebih cepat selesai, sedangkan dari segi biaya akan bertambah satu HK. Pada pengamatan penulis saat pemupukan di lapangan, jika jam kerja digunakan dengan baik maka output yang dihasilkan bisa lebih besar daripada standar kebun.

\section{Gejala defisiensi hara}

Darmosarkoro (2003) menyatakan bahwa unsur hara yang mendapat perhatian dalam pemupukan tanaman kelapa sawit meliputi N, P, K, Mg, Cu, dan B. Ketersediaan hara tersebut dalam tanah yang rendah mengakibatkan tanaman mengalami gejala defisiensi hara. Tanaman yang mengalami gejala defisiensi hara umumnya menunjukkan gejalagejala yang khas. Adiwiganda (2007) menambahkan bahwa gejala kekahatan atau defisiensi salah satu unsur hara dapat dideteksi secara visual pada daun. Berikut adalah status hara daun di PAGE tahun 2010 (Tabel 6).

Tabel 6. Status hara daun di PAGE tahun 2010

\begin{tabular}{lcccccc}
\hline \multirow{2}{*}{ Kriteria } & \multicolumn{7}{c}{ Status Hara Daun (\%) } \\
\cline { 2 - 7 } & $\mathrm{N}$ & $\mathrm{P} 2 \mathrm{O} 5$ & $\mathrm{~K} 2 \mathrm{O}$ & $\mathrm{MgO}$ & $\mathrm{Cu}$ & $\mathrm{B}$ \\
\hline Exses & 2 & 0 & 0 & 15 & 2 & 1 \\
Tinggi & 65 & 46 & 13 & 50 & 53 & 58 \\
Optimum & 22 & 52 & 29 & 33 & 29 & 38 \\
Rendah & 0 & 0 & 0 & 2 & 11 & 1 \\
Defisiensi & 10 & 2 & 58 & 0 & 5 & 2 \\
\hline
\end{tabular}

Sumber : data Department Research BGA (2010)

Tabel 6 menyajikan status hara daun berdasarkan luasan tanaman kelapa sawit. Secara umum status hara tanaman kelapa sawit di PAGE menunjukkan kondisi optimum-tinggi untuk unsur $\mathrm{N}, \mathrm{P}, \mathrm{Mg}, \mathrm{Cu}$, dan $\mathrm{B}$. Namun tanaman kelapa sawit mengalami defisiensi hara lebih dari 50 \% unsur K2O. Demikian juga dengan pengamatan visual di lapangan, banyak ditemukan tanaman yang mengalami gejala defisiensi hara $\mathrm{K}$, khususnya areal tanah gambut dan tanah berpasir. Gejala defisiensi hara $\mathrm{K}$ disebabkan pemupukan $\mathrm{K}$ yang tidak efektif dan efisien di lapangan serta penggunaan pupuk kalium dengan mutu kurang baik. Selain itu defisiensi hara bisa disebabkan pemupukan yang tidak berimbang untuk setiap jenis pupuk dan realisasi pemupukan yang belum sesuai dengan rekomendasi pemupukan. Akibatnya, akan menurunkan produksi dan prduktivitas tanaman kelapa sawit tahun berikutnya.

\section{Pemupukan dan produktivitas tanaman}

Kelas kesesuaian lahan potensialnya adalah S3 (agak sesuai) memiliki dua faktor pembatas yaitu drainase terhambat dan $\mathrm{pH}$ antara 3.5 - 4.0. Kenaikan kelas kesesuaian lahan dapat dilakukan dengan perbaikan yaitu pembuatan parit-parit drainase dan pemupukan (PPKS, 2003). Salah satu faktor yang mempengaruhi produksi dan produktivitas kelapa sawit adalah pemupukan. Produktivitas kelapa sawit di PAGE mengalami peningkatan setiap tahunnya. Produktivitas TBS di PAGE dapat dilihat pada tabel 7. Produktivitas kelapa sawit pada umur TM 1 sampai TM3 masih dibawah standar produktivitas kelas lahan S3. Namun pada umur TM 4 produktivitasnya telah mencapai bahkan 
melebihi standar produktivitas. Rata-rata produktivitas TBS di PAGE tidak jauh berbeda dengan standar produktivitas pada kelas lahan S3. Hal ini menunjukkan bahwa realisasi pemupukan di PAGE telah berjalan dengan baik sesuai dengan rekomendasi pemupukan sehingga dapat tercapai keefektifan dan efisiensi pemupukan. Selain itu, pihak kebun telah melakukan perbaikan yang menjadi faktor pembatas kelas kesesuaian lahan S3.

Tabel 7. Produktivitas TBS di PAGE tahun 2007-2010

\begin{tabular}{ccc}
\hline Tahun tanam & $\begin{array}{c}\text { Rata-rata produktivitas } \\
\text { (ton/ha/tahun)* }\end{array}$ & Standar produktivitas kelas lahan S3 (ton/ha/tahun)** \\
\hline 1 & 4.14 & 6.2 \\
2 & 8.31 & 12 \\
3 & 13.13 & 14.5 \\
4 & 17.1 & 17 \\
\hline
\end{tabular}

Sumber : *) data kebun PAGE (2011); ${ }^{* *}$ ) PPKS (2003)

\section{Hambatan dan kendala pemupukan}

Permasalahan yang ditemukan selama kegiatan pemupukan antara lain penyimpanan pupuk, penguntilan, pelangsiran dan pengecekan serta penaburan pupuk. Gudang penyimpanan pupuk khususnya pupuk yang telah diuntil belum memadai. Pupuk yang telah diuntil hanya ditutupi terpal. Pada saat hujan, pupuk akan terkena air hujan sehingga mengakibatkan pupuk membatu. Takaran untilan yang digunakan belum dikalibrasi dengan tepat sesuai dengan jenis dan dosis pupuk. Untuk jenis pupuk yang sama kadang menggunakan takaran yang sama. Kurangnya pengawasan dalam kegiatan penguntilan. Uji petik atau penimbangan sampel untilan jarang dilakukan untuk mengontrol ketepatan dosis untilan. Kesulitan dalam penentuan jumlah pupuk dengan tepat dikarenakan jumlah pohon yang berbeda antara rekomendasi dengan yang ada dilapangan sehingga pada saat pelangsiran maupun pengeceran pupuk di lapangan jumlah untilan kadang lebih atau kurang. Oleh karena itu perlu dilakukan sensus pokok secara rutin untuk menentukan jumlah tanaman dan kondisi blok. Masih terdapat pohon yang tidak teraplikasi khususnya ditengah baris tanaman. Pupuk sering tercecer di pasar pikul dan di TPH.

Hal yang menjadi kendala dan penghambat dalam pelaksanaan pemupukan antara lain: masih ditemukan piringan yang bergulma pada saat aplikasi pupuk, belum sepenuhnya dilakukan konservasi lahan khususnya lahan miring dan daerah genangan. Pada saat musim hujan akses jalan ke beberapa blok tidak dapat dilalui oleh truk mengakibatkan pemupukan pada blok tersebut tertunda. lahan bergambut, jumlah titi panen yang kurang dan tidak layak menjadi kendala bagi tenaga kerja pengecer dan penabur masuk ke dalam blok.

\section{KESIMPULAN}

Secara umum manajemen kebun di PAGE telah dilaksanakan dengan benar sesuai dengan standar operasional prosedur (SOP) yang berlaku mulai dari kegiatan pemeliharaan sampai dengan panen. PAGE telah menerapkan program BMS (Blok Manuring System), BSS (Blok Spraying System), dan BHS (Blok Harvesting System) dalam teknik budidaya kelapa sawit yaitu suatu program yang dilaksanakan secara simultan dengan tenaga kerja yang terorganisir dengan jelas. Program tersebut diharapkan dapat meningkatkan kuantitas dan kualitas kerja di kebun. Produksi TBS di PAGE mengalami peningkatan setiap tahun dan rata-rata produktivitasnya tidak jauh berbeda dengan standar produktivitas pada kelas lahan S3. Pihak kebun telah melakukan upaya perbaikan yang menjadi faktor pembatas lahan dimana sebagian besar tergolong pada kelas lahan S3.

Manajemen pemupukan di Pelantaran Agro Estate (PAGE) secara umum telah dilaksanakan sesuai dengan standar pemupukan yang benar. Pihak kebun telah memperhatikan ketentuan dan rekomendasi pemupukan yang telah dianjurkan serta telah mengacu pada prinsip $4 \mathrm{~T}$ (tepat waktu, jenis, dosis, dan cara) dalam hal mencapai keefektifan dan efisiensi pemupukan. Namun dalam penggunaan tenaga kerja belum efisien yang tentunya berdampak pada efisiensi waktu dan biaya. Realisasi pemupukan belum sepenuhnya dilaksanakan sesuai dengan 
rekomendasi. Hal ini dapat diketahui pada tanaman kelapa sawit yang masih mengalami gejala defisiensi hara. Akibatnya akan terjadi penurunan produksi dan produktivitas kelapa sawit. Kendala dalam pelaksanaan pemupukan masih ditemukan pada kondisi areal yang berawa dan bergelombang.

\section{DAFTAR PUSTAKA}

Adiwiganda, R. 2007. Manajemen Tanah dan Pemupukan Kelapa Sawit. Dalam S. Mangoensoekarjo (Ed.). Manajemen Tanah dan Pemupukan Budidaya Tanaman Perkebunan. Yogyakarta (ID) : Gajah Mada University Press.

Darmosarkoro, W. 2003. Defisiensi dan Malnutrisi Hara pada Tanaman Kelapa Sawit. Dalam W. Darmosarkoro, E.G. Sutarta, dan Winarna (Eds.). Lahan dan Pemupukan Kelapa Sawit. PPKS. Medan.

Direktorat Jenderal Perkebunan 2010. Statistik. [Internet] [diunduh 2010 Ags 01].
Tersedia

pada http//www.ditjenbun.deptan. go.id.

Poeloengan, Z., M.L. Fadli, Winarna, S. Rahutomo, dan E.S. Sutarta. 2003. Permasalahan Pemupukan pada Kelapa Sawit. Dalam W. Darmosarkoro, E.G. Sutarta, dan Winarna (Eds.). Lahan dan Pemupukan Kelapa Sawit. PPKS. Medan.

PPKS. 2003. Potensi dan Peluang Kelapa Investasi Industri Kelapa Sawit di Indonesia. PPKS. Medan.

Riwandi. 2002. Rekomendasi pemupukan kelapa sawit berdasarkan analisis tanah dan tanaman. Akta Agrosia 5(1):27-34.

Sutarta, E.S., S. Rahutomo, W. Darmosarkoro, dan Winarna. 2003. Peranan Unsur Hara dan Sumber Hara pada Pemupukan Kelapa Sawit. Dalam W. Darmosarkoro, E.G. Sutarta, dan Winarna (Eds.). Lahan dan Pemupukan Kelapa Sawit. PPKS. Medan 